\title{
E-Selectin Expression Increased in Human Ruptured Cerebral Aneurysm Tissues
}

\author{
Wenqing Jia, Rong Wang, Jizong Zhao, Isabelle Yisha Liu, Dong Zhang, \\ Xuejiang Wang, Xiaodi Han
}

\begin{abstract}
Objectives: The purpose of the present study is to investigate the expression of inflammation factor endothelial-leukocyte adhesion molecule (E-selectin, CD62E) in cerebral aneurysm walls and its relationship with aneurysm rupture. Methods: Cerebral aneurysm tissue samples were collected at the time of surgical clipping of nine patients with history of subarachnoid hemorrhage, and then compared with control artery tissues from the superficial temporal arteries (STA) of five patients with intracranial tumors. Immunohistochemistry (IHC) was performed to reveal and localize E-selectin expression in the aneurysms and artery tissues. Western blot analysis was used to relatively quantify the level of E-selectine protein expression in cerebral aneurysms when compared with normal arteries. Results: E-selectin was detected in the wall of all the aneurysm tissue samples and was rarely found in normal control arteries by IHC, and it was concentrated in proliferating and disorganized epithelia cells. Moreover, with the Western blot method, the E-selectin protein level increased significantly in aneurysm tissues compared to normal STA. Conclusions: E-selectin might be an important factor involved in the process of cerebral aneurysm formation and rupture, by promoting inflammation and weakening cerebral artery walls.
\end{abstract}

RÉSUMÉ: Augmentation de l'expression de la E-sélectine dans des tissus humains après rupture d'un anévrisme cérébral. Objectifs : Le but de cette étude était d'étudier l'expression d'un facteur de l'inflammation, la molécule d'adhésion des leucocytes aux cellules endothéliales (E-sélectine, $\mathrm{CD} 62 \mathrm{E}$ ) dans la paroi d'anévrismes cérébraux et sa relation à la rupture de l'anévrisme. Méthode : Des échantillons de tissus d'anévrismes cérébraux ont été recueillis au moment d'une chirurgie pour mettre en place un clip chez 9 patients qui avaient subi une hémorragie sous-arachnoïdienne et nous les avons comparés à du tissu artériel témoin provenant d'artères temporales superficielles (ATS) provenant de 5 patients atteints de tumeurs intracrâniennes. L'immunohistochimie (IHC) a révélé et localisé l'expression de l'E-sélectine dans les tissus provenant des anévrismes et des artères. L'analyse par buvardage Western a été utilisée pour quantifier relativement le niveau d'expression d'E-sélectine dans les anévrismes cérébraux et les artères normales. Résultats : L'E-sélectine a été détectée par IHC dans la paroi de tous les anévrismes et rarement dans celle des artères témoins normales et elle était surtout localisée dans les cellules épithéliales en prolifération et sans organisation. De plus, le niveau d'E-sélectine au buvardage Western était significativement plus élevé dans les tissus anévrismaux que dans les ATS normales. Conclusions : L’E-sélectine pourrait être un facteur important dans le processus de formation des anévrismes cérébraux et particulièrement leur rupture, en favorisant l'inflammation et l'affaiblissement de la paroi artérielle.

Can. J. Neurol. Sci. 2011; 38: 858-862

The prevalence of intracranial aneurysm in humans is about $6 \%{ }^{1,2}$. Data from the United States show 200 million to 1 billion people worldwide with unruptured aneurysm ${ }^{3}$. Most aneurysm patients die of rupture of the aneurysms with subarachnoid hemorrhage $(\mathrm{SAH})$ and following vasospasm. Therefore, the reasons behind cerebral aneurysm rupture is of the most important factors under investigation. Even though hemodynamics studies showed blood flow and intralumenal pressure change had major effect on the formation of aneurysms, which based on other evidences, such as the fact that cerebral aneurysms characteristically occur at the branch points of major cerebral arteries and, more commonly, at the internal carotidposterior communicating artery and anterior cerebral-anterior communicating artery junctions, more and more research reveals that inflammation reactions might be another important factor in the formation and rupture of cerebral aneurysms.
As a natural response to injury, inflammation is generally beneficial, facilitating the initial repair of damaged tissue. When persistent, however, inflammation may have deleterious effects ${ }^{4}$. Histopathological studies on clipped human aneurysms have identified macrophages and lymphocytes in the aneurysm wall. These cell types are indicators of inflammation ${ }^{5,6}$.

From the Department of Neurosurgery (WJ, RW, JZ, DZ), Department of Pathology (XW), TianTan Hospital, School of Basic Medical Sciences, Capital Medical University; Department of Neurosurgery (XH), Beijing Tiantan Puhua Hospital, Beijing China; Washington University (IYL), School of Medicine, St. Louis, Missouri; Department of Neurosurgery (XH), University of Rochester Medical Center, New York, New York, USA.

Received June 23, 2010. Final Revisions Submitted May 16, 2011 Correspondence to: Jizong Zhao, Department of Neurosurgery, TianTan Hospital, Capital Medical University, Beijing China, 100050. 
Although the balance between pro-inflammatory and antiinflammatory cytokines is likely to determine the level and persistence of inflammation, the contribution of these factors to aneurysm-related inflammation is not known. E-selectin is an important endothelia adhesion molecule which helps monocytes adhere to endothelial cells. These activated monocytes then infiltrate into the wall of the artery to become foam cells and cause injury to the artery by secreting metalloproteases ${ }^{7}$. The role of inflammation in atherosclerosis ${ }^{8-10}$, abdominal aortic aneurysm, ${ }^{11-13}$ and arteritis ${ }^{14}$ has been demonstrated. Therefore we sought to elucidate the role of inflammation during the formation and rupture of intracranial aneurysms. Even though recent studies showed that, following $\mathrm{SAH}$, E-selectin increased in cerebrospinal fluid (CSF) and serums ${ }^{15}$, there is no report about E-selectin expression in ruptured aneurysms tissues. This study is to investigate the protein expression of endothelia adhesion molecular E-selectin in cerebral aneurysm walls of human surgical samples.

\section{Patients And Methods}

Patients and surgical aneurysm samples: From October 2007 to December 2008, more than 200 patients with intracranial aneurysms were treated microsurgically at the Neurosurgery Department of Tiantan Hospital in Beijing, China. All the aneurysms were clipped. We collected nine aneurysm wall specimens after they were clipped. Five were from men and four were from women with a median age of 42 years (range 18-59 years). All of the operations were performed within five days after subarachnoid hemorrhage was diagnosed (seven of them within three days, one at four days and one at five days). All of the specimens were from berry aneurysms smaller than $2.5 \mathrm{~cm}$. All of the aneurysms were from the Circle of Willis, with one from the anterior communicating artery (AComA), two from the PComA, one from ACA and five from the MCA. Six tissue samples were stored in liquid nitrogen for molecular biology studies. The other three tissue samples were each divided in half, with one half of the tissue stored in liquid nitrogen and the other half stored in Bouin's solution for immunohistochemistry studies.

The distal portion of the superficial temporal artery (STA) from five patients undergoing surgery for intracranial tumors was used as a control group. All the STA samples were obtained during frontal-temporal craniotomy with the patient's informed consent. Two tissue samples were stored in liquid nitrogen for molecular biology studies. The other three tissue samples were each divided in half, with one half stored in liquid nitrogen and the other half stored in Bouin's solution for immunohistochemistry studies. All individuals included in the study were Chinese.

Histopathological Evaluation: Hematoxylin and Eosin (H\&E) and immunohistochemistry (IHC) staining were performed for the tissue samples. Briefly, $5 \mu \mathrm{m}$ thickness paraffin sections were deparaffinized and rehydrated in water, in addition to standard H\&E staining, sections for IHC were rinsed in phosphate buffered saline (PBS) and then placed into a microwave oven, with the $0.01 \mathrm{M}$ Citrate buffer of $\mathrm{pH} 6.0$, in temperatures between $92-98^{\circ} \mathrm{C}$ for 15 minutes (min) for antigen retrieval, then cooled down for $20 \mathrm{~min}$ at room temperature, after a PBS rinse, and kept in $3 \% \mathrm{H}_{2} \mathrm{O}_{2}$ at room temperature for $20-30$ min to inactivate the activity of the peroxydase. After rinsing in PBS, sections were incubated in blocking solution (5\% goat serum with $0.1 \%$ Triton $\mathrm{X}-100$ ) for $60 \mathrm{~min}$, then incubated overnight at $4{ }^{\circ} \mathrm{C}$ with E-selectin rabbit polyclonal antibody (1:400, Abcam) diluted in 5\% normal goat serum and $0.1 \%$ Triton X-100. The following day, sections were rinsed in PBS and placed in biotinylated goat anti-rabbit antibody (1:200, Vector Laboratories) for one hour at room temperature and then in $3 \% \mathrm{H}_{2} \mathrm{O}_{2} / \mathrm{PBS}$ for ten minutes, followed by application of avidin-biotin complex (ABC) kit (Vector Laboratories) and visualized with diaminobenzidine (DAB) for quantification. Sections were counterstained with campeachy and mounting with Canada balsam and cover slipped. Image analysis was done using a Leica Q500 microscope.

Western Blot Analysis: Control and aneurysm tissues were homogenized in ice-cold lyses' buffer containing $0.5 \%$ Nonidet P-40 (vol/vol), $25 \mathrm{mmol} / \mathrm{L} \mathrm{N}$-2-hydroxyethylpiperazine-N'-2ethanesulfonic acid, $\mathrm{pH} 7.4,150 \mathrm{mmol} / \mathrm{L} \mathrm{NaCl}, 1 \mathrm{mmol} / \mathrm{L}$ ethylenediamine tetra-acetic acid, $1 \mathrm{~mol} / \mathrm{L}$ sodium orthovanadate, and a cocktail of protease inhibitors. Homogenates were centrifuged at $13,000 \mathrm{~g}$ in a microcentrifuge at $4^{\circ} \mathrm{C}$, and the protein concentrations were determined from the supernatants using the Bio-Rad protein assay. Proteins (200 g) from control and aneurysm samples were separated on $12.5 \%$ SDS-PAGE with $5 \%$ SDS stacking gels prior to transfer onto nitrocellulose membrane (Amersham Biosciences, Piscataway, NJ). Unspecific antigen binding was blocked by incubation with $5 \%$ dry milk in TBS-Tween $20(0.05 \%$, Sigma) for $60 \mathrm{~min}$ and then washed $3 \mathrm{x}$ 5 min with TBS-Tween 20. The membranes were blocked for 1 hour in Tris-buffered saline with Tween $20(20 \mathrm{mmol} / \mathrm{L}$ Tris $\mathrm{HCl}$, $\mathrm{pH} 7.4,0.9 \% \mathrm{NaCl}$, and $0.05 \%$ Tween 20 ) containing $5 \%$ nonfat dried milk, followed by incubation with primary antibodies against E-selectin (rabbit polyclonal antibody (1:1000, Abcam). After extensive washing, Peroxidase-conjugated AffiniPure goat anti-rabbit immunoglobulin G (IgG) (1:5,000; Jackson Immuno Research Labs, West Grove, PA) were used for secondary incubations for two hours at room temperature. Reactive bands were visualized using an enhanced chemiluminescence detection system (Molecular Imager Gel Doc XR + and ChemiDoc XRS+ system, Bio-Rad Labratories, Hercules, CA). Immunoreactive bands indicating expression of E-selectin and protein levels were expressed as the optical density of the examined factor relative to $\beta$-actin within the same lane.

Statistical analysis: For comparing E-selectin expression positive cells and protein concentration in different groups, data are presented as means \pm SD. Statistical analysis by one-way analysis of variance (ANOVA) followed by the Student's t test. Probability $(\mathrm{p})$ values $<0.05$ are considered as significant.

\section{RESULTS}

Histological changes in aneurysm when compared with control artery wall: By $\mathrm{H} \& \mathrm{E}$ staining, the three-layered structure of the aneurysm wall has been destroyed. Thrombosis can be found in most of the aneurysms' cavity. Fibrous degeneration caused thickening of the aneurysm's inner membranes. The continuity of endothelial cell liner in lumen destroyed but with cell proliferation, the proliferation cells are out of organization. The artery media is infiltrated with hyperplasic fiber components, monocytes, and accrementition 


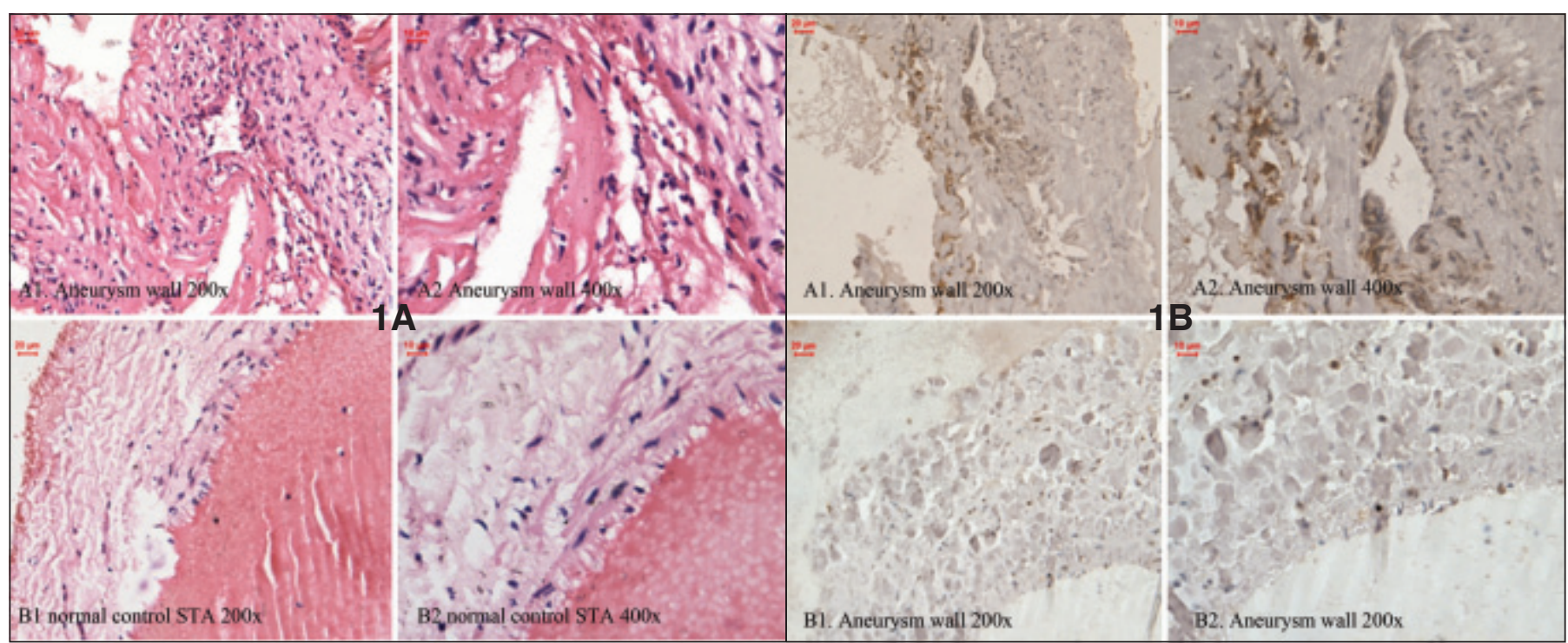

Figure 1: A) Hematoxylin and Eosin (H\&E) staining showed aneurysm wall pathology changes (A1 200x and A2 400x) when compared with normal superficial temporal artery (STA) wall (B1 200x and B2 400x). Aneurysm walls were disorganized with epithelial cell proliferation and artery media infiltrated with hyperplastic fiber components, monocytes, and accrementition nutrient vessels similar to granulation tissue. B) Immunohistochemistry showed E-selectin protein (brown) can be found mainly in aneurysms (A1 200x, A2 400x) but less in normal control artery (STA) walls (B1 200x, B2 $400 x)$.

nutrient vessel similar to granulation tissue (Figure 1A). The normal control tissue which comes from superficial temporal arteries is a muscular artery, consisting of an inner membrane, media, and outer membrane. The inner membrane is composed of a single layer of endothelial cells and a well developed inner elastic layer. The media is composed of smooth muscle loops with longitude muscle fibers. The outer membrane is composed of connective tissue without an outer elastic membrane (Figure 1B).

E-selectin can be detected in cerebral arteries but not control artery walls by immunohistochemistry and Western Blot: In this study, we found that E-selectin protein is located in the cell cytoplasm with small amounts in the nucleus in all aneurysm walls (mean grey $0.266 \pm 0.062$ ). We found less Eselectin protein in control artery walls (mean grey $0.213 \pm 0.019$ ) (Figure 2, $\mathrm{P}<0.05$ ), which indicated that E-selectine is a specific factor in the aneurysm wall. By Western blot, the relative protein level was quantified and compared to $\beta$-actin. E-selectin protein increased significantly in cerebral aneurysm tissues $(1.5437 \pm 0.0602)$ when compared to normal control artery tissue $(0.4281 \pm 0.0634)$ (Figure 3A,B), with $\mathrm{P}<0.05$.

\section{DISCUSSION}

This is the first study to demonstrate the expression of endothelia adhesion molecule E-selectin (CD62E) protein expression in ruptured human aneurysm walls using surgical resection tissue samples obtained during clipping operations. We found that E-selectin protein expression increased significantly in ruptured aneurysm walls when compared with control STA walls using immunohistochemistry and Western blot methods. E-selectin was exclusively expressed on the endothelial cell membrane which is consistent with previous reports ${ }^{15}$. As an

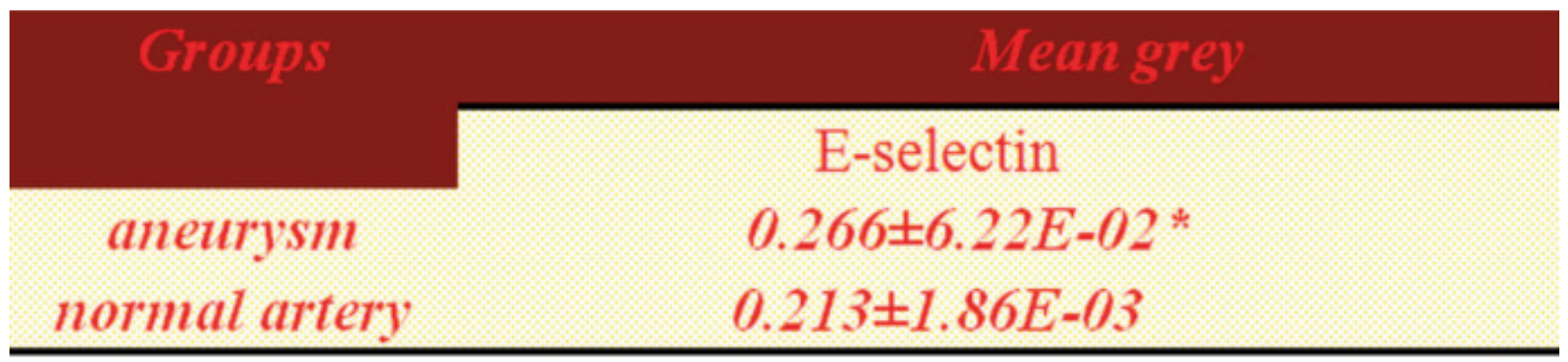

Figure 2: Mean grey of positive E-selctin in aneurysm and normal artery wall by IHC, E-selectin is significantly increased in grey when compared with normal control, $p<0.05 . * p<0.05$ Differences were considered statistically significant. 


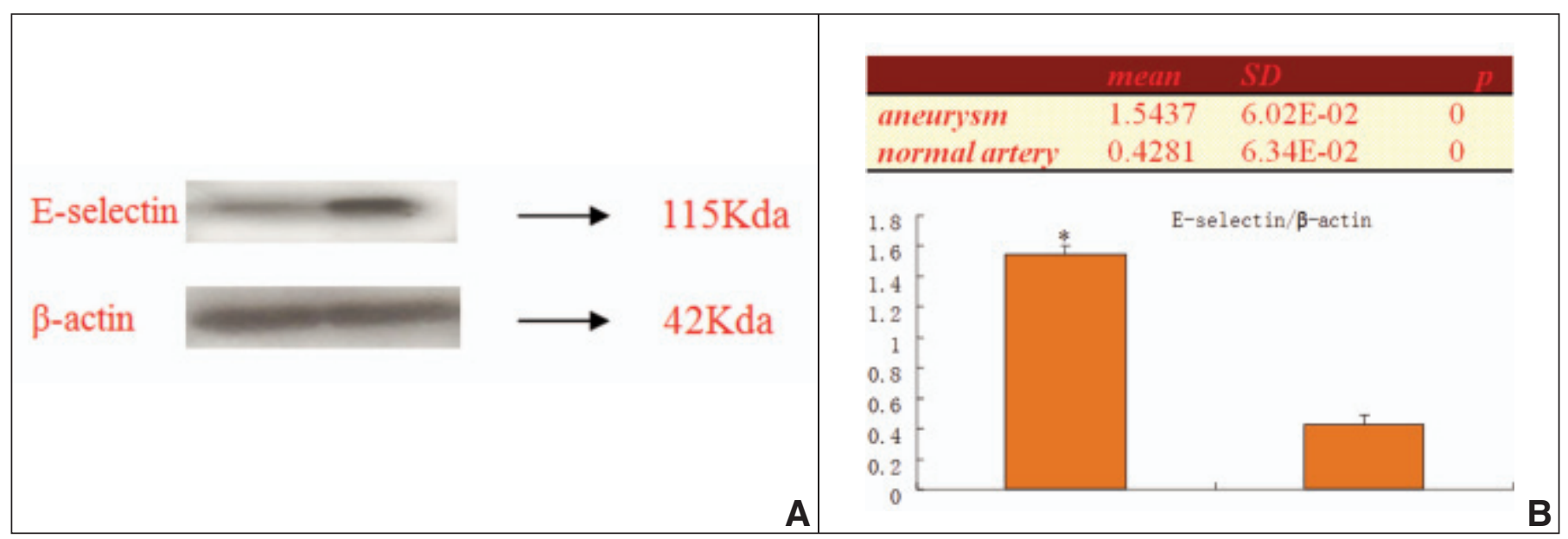

Figure 3: Semi-qualification of E-selectin protein levels in aneurysm tissues and normal STA artery walls by Western Blots. The level of E-selectin $($ A.band $115 \mathrm{kda})$ when compared to loading control protein $\beta$-actin $(A$. band $42 \mathrm{kda})$ is increased significantly in aneurysm tissue $(B)$ with $p<0.01$.

A. B. ${ }^{*} p<0.01$ Differences were considered statistically significant.

adhesion molecule, E-selectin protein expression which is increased in the aneurysm walls, might be related to inflammation reactions in the formation and rupture of cerebral aneurysms.

Even though inflammation has been inferred as a possible reason of formation of aneurysms for many years ${ }^{16,17}$, the role of the inflammation in aneurysm rupture processes is still unknown ${ }^{17-20}$. There has been increasing focus on inflammatory factors within aneurysms in recent years. Strong evidence is that when compared with controls, many adhesions molecules such as ICAM-1, VCAM-1, and L-selectin levels in the CSF of SAH patients were increased had been reported ${ }^{15}$. Immunohistochemistry and immunofluorescence, an increased activation of C3 and C9, increased deposition of $\operatorname{IgG}$ and $\operatorname{IgM}$, increased expression of VCAM-1, as well as higher numbers of macrophages, monocytes, and T-lymphocytes in the tissues from the aneurysms had been found ${ }^{21,22}$. These findings suggest that an inflammatory process occurrs in the walls of intracranial aneurysms.

The main process of inflammation is shown in Figure 4. The cascade reaction that results in leukocyte activation involves cell adhesion factors, including selectins, integrins, and immunoglobulins. Selectins can be divided into E-, P-, and Lselectin. E-selectin mediates inflammation early on in the process. It mediates the adhesion and transfer of leukocytes into the artery wall. E-selectin also appears in activated endothelial cells during the inflammatory reaction.

Soluble E-selectin was demonstrated to be rapidly shed from surfaces of endothelial cells on cellular activation and therefore could be detected in serum and CSF. Most research has been concentrated on aneurysms related to $\mathrm{SAH}$ and cerebral ischemia. For example, Frijns et $\mathrm{al}^{23}$ studied $106 \mathrm{SAH}$ patients and found that serum E-selectin levels were significantly decreased in patients who suffered from cerebral ischemia within $^{24}$ hours after their aneurysm was clipped. The E-selectin levels of the other patient did not change significantly. It was proposed that the serum levels of cell adhesion factors like E- selectin may not be used to evaluate the prognosis of aneurismal SAH patients. Nissen et al showed that serum E-selectin level in cerebral ischemia patients were decreased ${ }^{24}$. Therefore, even though it is easy to obtain blood serum values for aneurysm patients for E-selectin level evaluation, the results do not reflect the local cerebral aneurysm wall inflammation situation. On the other hand, CSF may be more reliable when tested together with serum E-selectin. Tanriverdi ${ }^{25}$ et al found that serum and CSF Eselectin levels were significantly increased in aneurismal SAH patients as compared with patients with hydrocephalus. Cerebrospinal fluid E-selectin levels in the aneurismal SAH patients who had vasospasm were higher than other patients. Because of the above contradictiory results in cerebral aneurysm patients, the direct method for detecting the E-selectin levels should be by testing aneurysm wall tissues rather than serum and

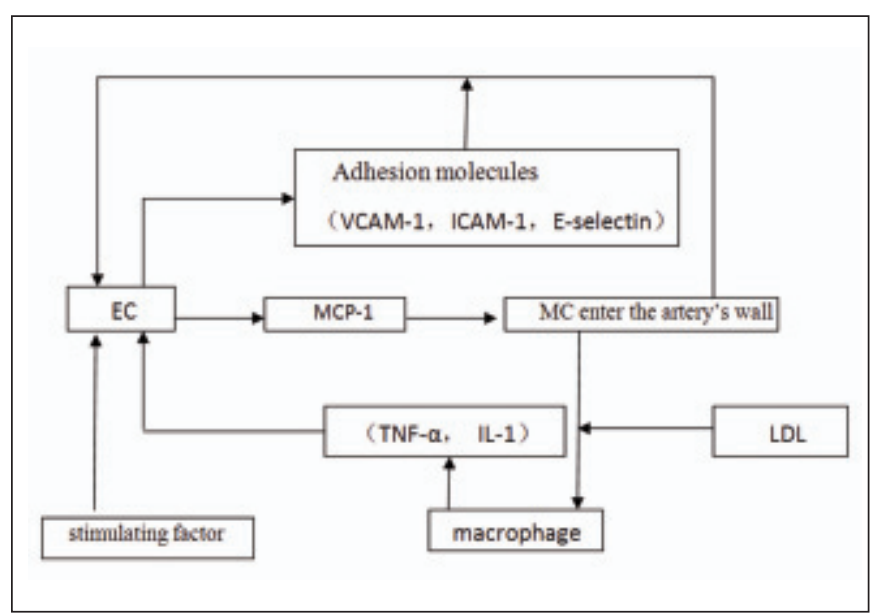

Figure 4: Possible mechanism of E-selectin in the inflammation process of aneurysm formation. 
CSF levels. Our patients all had SAH, which indicated aneurysm rupture history. We found a significant increase in E-selectin levels in the walls of aneurysms locally using Western blot and immunohistochemistry. This direct evidence suggests that Eselectin might have a role in the formation and rupture of human cerebral aneurysms. Further studies should be done in unruptured and ruptured aneurysms and serum and CSF levels compared in the same patients to reveal more details of Eselectin role in this process.

\section{Conclusion}

Increased E-selectin expression may have deleterious effects on cerebral arteries by promoting inflammation, which can weaken vessel walls and induce formation of cerebral aneurysms. Blocking E-selectin pathways may be effective in preventing the formation or rupture of cerebral aneurysms.

\section{ACKNOWLEDGEMENTS}

This study was supported by a foundation from Capital Medical University basic and clinic associate project.

\section{REFERENCES}

1. Chyatte D. The epidemiology, genetics and clinical behavior of intracranial aneurysms. In: Awad IA, editor. Current management of cerebral aneurysms. Park Ridge: AANS; 1995. p. $1-20$.

2. Stehbens WE. Aneurysms and anatomical variations of cerebral arteries. Arch Pathol. 1963; 75: 45-64.

3. Berenstein A, Flamm ES, Kupersmith MJ. Unruptured intracranial aneurysms. N Engl J Med. 1999; 340: 1439-40.

4. Laroux FS. Mechanisms of inflammation: the good, the bad and the ugly. Front Biosci. 2004; 9: 3156-62.

5. Chyatte D, Bruno G, Desai S, Todor DR. Inflammation and intracranial aneurysms. Neurosurgery.1999; 45: 1137-46.

6. Frosen J, Piippo A, Paetau A, et al. Remodeling of saccular cerebral artery aneurysm wall is associated with rupture: Histological analysis of 24 unruptured and 42 ruptured cases. Stroke. 2004; 35: 2287-93.

7. Yang PY, Rui YC. Intercellular adhesion molecule and vascular endothelial growth factor expression kinetics in macrophage derived foam cells. Life Sci. 2003; 74: 471-80.

8. Hansson GK. Immune and inflammatory mechanisms in the pathogenesis of atherosclerosis. J Atheroscler Thromb [Suppl 1]. 1994; 6-9.

9. Henry PD, Chen $\mathrm{CH}$. Inflammatory mechanisms of atheroma formation: influence of fluid mechanics and lipid-derived inflammatory mediators. Am J Hypertens. 1993; 6: 328-34.
10. Ross R. Atherosclerosis: an inflammatory disease. N Engl J Med. 1999; 340: 115-26.

11. Freestone T, Turner RJ, Coady A, et al. Inflammation and matrix metalloproteinases in the enlarging abdominal aortic aneurysm. Arterioscler Thromb Vasc Biol. 1995; 15: 1145-51.

12. Koch AE, Haines GK, Rizzo RJ, et al. Human abdominal aortic aneurysms: immunophenotypic analysis suggesting an immunemediated response. Am J Pathol. 1990; 137: 1199-213.

13. Pearce WH, Koch AE. Cellular components and features of immune response in abdominal aortic aneurysms. Ann NY Acad Sci. 1996; 800: 175-85.

14. Weyand CM, Hicok KC, Hunder GG. The HLA-DRB1 locus as a genetic component in giant cell arteritis: Mapping of a diseaselinked sequence motif to the antigen binding site of the HLA-DR molecule. J Clin Invest. 1992; 90: 2355-61.

15. Polin RS, Bavbek M, Shaffrey ME. Detection of soluble E-selectin, ICAM-1, VCAM-1 and L-selectin in the cerebrospinal fluid of patients after subarachnoid haemorrhage. J Neurosurg. 1998; 89: 559-67.

16. Virchow VR. Uber die akute Entzundung der Arterien. Virchows Arch A Pathol Anat Histopathol. 1947; 1: 272-378.

17. Handler FP, Blumenthal HT. Inflammatory factors in the pathogenesis of cerebrovascular aneurysms. JAMA. 1954; 155: 1479-83.

18. Ryba M, Jarzabek-Chorzelska M, Chorzelski T, et al. Is vascular angiopathy following intracranial aneurysm rupture immunologically mediated? Acta Neurochir (Wien). 1992; 117: 34-7.

19. Kosierkiewicz TA, Factor SM, Dickson DW. Immunocytochemical studies of atherosclerotic lesions of cerebral berry aneurysms. J Neuropathol Exp Neurol. 1994; 53: 399-406.

20. Schievink WI. Intracranial aneurysms. N Engl J Med. 1997; 336: 28-40.

21. Stehbens WE. Etiology of intracranial berry aneurysms. J Neurosurg. 1989; 70: 823-31.

22. Chyatte D, Bruno G. Inflammation and intracranial aneurysms. Neurosurgery. 1999; 45: 1137-56.

23. Frijns CJM, Kasiu KM, Algra A. Endothelial cell activation markers and delayed cerebral ischaemia in patients with subarachnoid haemorrhage. J Neurol Neurosurg Psychiatry. 2006; 77: 863-7.

24. Nissen JJ. Serum concentration of adhesion molecules in patients with delayed ischemic neurological deficit after aneurysmal subarachnoid hemorrhage: the immunoglobulin and selectin superfamilies. J Neurol Neurosurg Psychiatry. 2001; 71: 329-33.

25. Tanriverdi T, Sanus GZ, Ulu MO et al. Serum and cerebrospinal fluid concentrations of E-selectin in patients with aneurismal subarachnoid hemorrhage. Braz J Med Biol Res. 2005; 38: 1703-10. 